\title{
Colon Carcinoma with Unusual Metastasis to the Esophagus Manifesting as Multiple Nodules and Dysphagia: Management with Systemic Chemotherapy
}

\author{
Pankaj G. Vashi Digant Gupta Bradford Tan \\ Cancer Treatment Centers of America ${ }^{\circledR}$ at Midwestern Regional Medical \\ Center, Zion, III., USA
}

\section{Key Words}

Colon carcinoma · Metastasis - Esophagus · Dysphagia · Endoscopy

\begin{abstract}
We present here the rare clinical case of a 44-year-old gentleman with metastasis from colon carcinoma to the esophagus presenting with multiple nodules and dysphagia, which was successfully managed with systemic chemotherapy. The patient presented at our institution with 3-month history of dysphagia almost 4 years after being operated for stage III carcinoma in the sigmoid colon. Endoscopic findings showed multiple nodules at the gastroesophageal junction and mid esophagus. Histological features and immunostains confirmed the diagnosis of metastatic colon carcinoma. Because of evidence of extensive metastatic disease in the spine and liver requiring systemic therapy, the patient was treated with chemotherapy with irinotecan and cetuximab, with subsequent improvement in tumor markers, liver metastasis and symptoms of dysphagia. Even though repeat endoscopy showed no improvement in esophageal nodules, the overall response to chemotherapy was positive. In conclusion, we present a very rare, previously unreported case of metastases from colon cancer to the esophagus presenting as non-obstructive nodules and dysphagia that responded to systemic chemotherapy.
\end{abstract}

\section{Introduction}

Esophagus is an unusual metastatic site for tumors originating from distant organs. Autopsy studies suggest an incidence rate of 3-6\% of metastasis to the esophagus in patients dying of any type of cancer $[1,2]$. Several case reports in the literature have 
documented metastasis to the esophagus from a variety of primary tumor sites such as breast [1, 3-6], prostate [7], lung [1, 8, 9], liver [10], ovary [11], kidney [12] and rectum [13], with breast and lung being the most common. In addition, esophageal metastasis from colon cancer has also been described in one case who developed dysphagia due to esophageal stricture, which was successfully treated with surgical bypass and endoscopic prosthesis [14]. Here, we report the rare clinical case of a 44-year-old gentleman with metastasis from colon cancer to the esophagus in the form of multiple nodules presenting as dysphagia, which was successfully managed with systemic chemotherapy.

\section{Case Report}

We present a 44-year-old gentleman who experienced a change in bowel habits and felt a mass in the lower abdomen sometime in 2007. On colonoscopy, he was found to have malignant colon cancer in the sigmoid colon, which was surgically excised. He had 15 positive lymph nodes out of 18. With a stage III colon cancer diagnosis, he was started on adjuvant chemotherapy with leucovorin, 5 -fluorouracil, oxaliplatin and bevacizumab. Unfortunately, after one cycle, the patient became extremely sick and decided not to pursue any further treatments.

In June 2008, the patient started experiencing some pain in the back, and on further evaluation was found to have a metastatic lesion to the T1 spine. On biopsy, this was confirmed to be a metastasis from the colon. He had resumed chemotherapy at that point, along with radiation therapy for palliation. Over the next 3 years he was treated with multiple modalities of chemotherapy, which included capecitabine, oxaliplatin and bevacizumab (Avastin), followed by irinotecan and panitumumab. This was followed by a clinical trial. Unfortunately, the patient had progressive disease in the retroperitoneal lymph nodes and subsequently developed liver metastasis.

By February 2011, the patient had developed right-sided numbness, with MRI showing a cerebral thrombotic stroke. Chemotherapy was discontinued and the patient was just observed for the next few months. He started experiencing more pain in the lower back area and was found to have a metastatic lesion in the L3-L4 vertebrae, which was also treated with palliative radiation, with significant improvement. The right-sided weakness improved as well over a period of time. In June 2011, his chemotherapy was resumed with leucovorin, 5 -fluorouracil and oxaliplatin. A subsequent CT scan showed continued progressive disease in the liver as well as the retroperitoneal lymph nodes.

In October 2011, the patient started experiencing increasing difficulty in swallowing, mostly with solid foods. Upper endoscopy done at home showed only gastritis, with no evidence of any malignancy or esophagitis. The patient was treated with a high dose of pain medication for his abdominal and back pain, along with proton pump inhibitors, before he was seen at our institution in November 2011. A repeat upper endoscopy showed multiple non-obstructive nodules at the gastroesophageal junction (fig. 1) as well as more nodules in the mid esophagus. These nodules were biopsied. The pathology (histology and immunostains) confirmed these nodules to be metastasis from colon cancer (fig. 2). Because of evidence of extensive disease in the spine and liver requiring systemic management, the patient was treated with chemotherapy, which included irinotecan and cetuximab. After 3 cycles, the patient's tumor markers improved and CT scan also showed improvement in liver metastasis. The symptoms of dysphagia also had significantly improved. Three months later, a repeat upper endoscopy continued to show the same nodules in the esophagus, unchanged from previous evaluation. At this point, it was decided to continue systemic chemotherapy, since the patient's symptoms of dysphagia had significantly improved with the present treatment plan. 


\section{Discussion}

It is extremely rare for colon carcinoma to metastasize to the esophagus. We report here a case of sigmoid carcinoma metastasizing to the esophagus in the form of multiple nodules presenting as dysphagia. The uniqueness of our case is that in spite of absence of an obstructive lesion (with only small and nodular lesions), the patient was symptomatic. Symptom relief in dysphagia was achieved by systemic chemotherapy. The reason for not considering any local treatment was the presence of metastatic disease. Even though repeat endoscopy showed no improvement, the overall response to chemotherapy was positive. Our case also demonstrates that with newer drugs for colon cancer, the survival for advanced cancer can be prolonged, with our patient doing fairly well 5 years after been diagnosed with advanced cancer.

It has been suggested that since most patients with metastasis to the esophagus already have metastasis to other areas, the treatment of choice is usually chemotherapy and/or radiotherapy [2]. However, when the primary tumor growth rate is suspected to be slow, an aggressive surgical approach could be the therapeutic procedure of choice [14]. In our patient, because of extensive metastatic disease, we chose systemic chemotherapy over local endoscopic treatment. In the lone published case report of esophageal metastasis from colon carcinoma, since the primary tumor had been well controlled for 2 years without any evidence of metastatic disease, the treatment of choice was surgical bypass [14].

Secondary esophageal involvement from primary tumors of distant origin occurs via lymphatics or the bloodstream [1]. Most commonly, the spread to the esophagus occurs in submucosal location with normal overlying mucosa, presenting in the form of an esophageal stricture [1]. In our case, the key endoscopic finding was the presence of multiple small nodules as opposed to a malignant stricture.

In conclusion, we present a very rare, previously unreported case of metastases from colon cancer to the esophagus presenting as non-obstructive nodules and dysphagia that responded to systemic chemotherapy. Dysphagia in a patient with known colorectal carcinoma should always trigger a full gastrointestinal work-up, including endoscopy and biopsy. The treatment approach is primarily dictated by the status of the primary tumor as well as the extent of the metastatic spread.

\section{Acknowledgements}

This study was funded by Cancer Treatment Centers of America ${ }^{\circledR}$.

\section{Disclosure Statement}

All authors declare that there are no potential conflicts (financial, professional or personal) relevant to this paper. 


\begin{tabular}{r|l|l|l}
$\begin{array}{r}\text { Case Reports in } \\
\text { Gastroenterology }\end{array}$ & $\begin{array}{l}\text { Case Rep Gastroenterol 2012;6:484-488 } \\
\text { DOI: 10.1159/000341587 }\end{array}$ & $\begin{array}{l}\text { Published online: } \\
\text { July 24, 2012 }\end{array}$ & $\begin{array}{l}\text { @ 2012 S. Karger AG, Basel } \\
\text { ISSN 1662-0631 } \\
\text { www.karger.com/crg }\end{array}$ \\
\hline
\end{tabular}

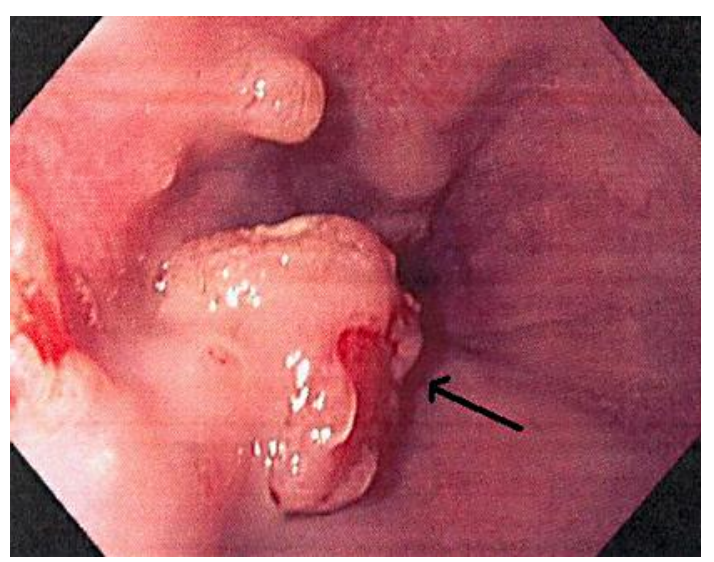

Fig. 1. Endoscopy showing multiple non-obstructive nodules at the gastroesophageal junction.

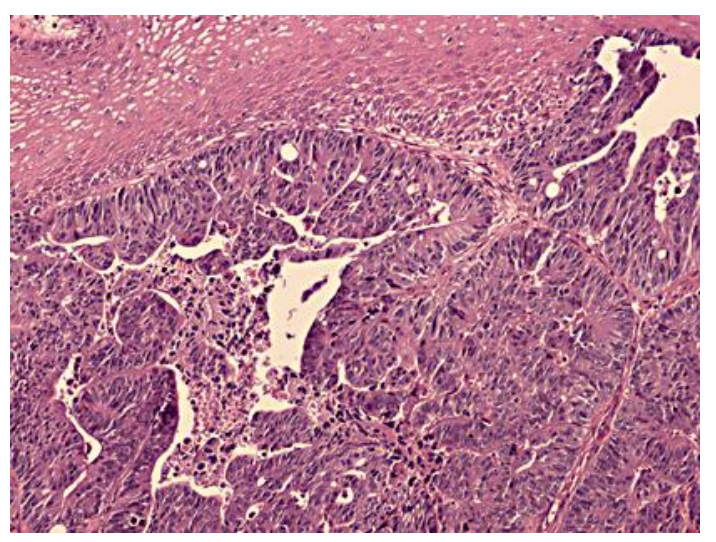

Fig. 2. Microscopic image (10x) of the tumor showing overlying benign esophageal squamous mucosa with infiltrating intestinal-type adenocarcinoma lined by columnar epithelial cells with elongated cigar-shaped nuclei, with luminal dirty necrosis.

\section{References}

-1 Simchuk EJ, Low DE: Direct esophageal metastasis from a distant primary tumor is a submucosal process: a review of six cases. Dis Esophagus 2001;14:247-250.

-2 Mizobuchi S, Tachimori Y, Kato H, Watanabe H, Nakanishi Y, Ochiai A: Metastatic esophageal tumors from distant primary lesions: report of three esophagectomies and study of 1,835 autopsy cases. Jpn J Clin Oncol 1997;27:410-414.

-3 Sunada F, Yamamoto H, Kita H, Hanatsuka K, Ajibe H, Masuda M, Hirasawa T, Osawa H, Sato K, Hozumi Y, Sugano K: A case of esophageal stricture due to metastatic breast cancer diagnosed by endoscopic mucosal resection. Jpn J Clin Oncol 2005;35:483-486.

-4 Wu CM, Hruban RH, Fishman EK: Breast carcinoma metastatic to the esophagus. CT findings with pathologic correlation. Clin Imaging 1998;22:343-345.

5 Koike M, Akiyama S, Kodera Y, Nakao A: Breast carcinoma metastasis to the esophagus: report of two cases. Hepatogastroenterology 2005;52:1116-1118.

6 Herrera JL: Case report: esophageal metastasis from breast carcinoma presenting as achalasia. Am J Med Sci 1992;303:321-323. 
-7 Nakamura T, Mohri H, Shimazaki M, Ito Y, Ohnishi T, Nishino Y, Fujihiro S, Shima H, Matsushita T, Yasuda M, Moriwaki H, Muto Y, Deguchi T: Esophageal metastasis from prostate cancer: diagnostic use of reverse transcriptase-polymerase chain reaction for prostate-specific antigen. J Gastroenterol 1997;32:236-240.

8 Oka T, Ayabe H, Kawahara K, Tagawa Y, Hara S, Tsuji H, Kusano H, Nakano M, Tomita M: Esophagectomy for metastatic carcinoma of the esophagus from lung cancer. Cancer 1993;71:2958-2961.

9 Hsu PK, Shai SE, Wang J, Hsu CP: Esophageal metastasis from occult lung cancer. J Chin Med Assoc 2010;73:327-330.

10 Tsubouchi E, Hirasaki S, Kataoka J, Hidaka S, Kajiwara T, Yamauchi Y, Masumoto T, Hyodo I: Unusual metastasis of hepatocellular carcinoma to the esophagus. Intern Med 2005;44:444-447.

11 Asamura H, Goya T, Hirata K, Suemasu K, Itabashi M, Matsuno Y, Hirota T: Esophageal and pulmonary metastases from ovarian carcinoma: a case report of long-term survival following metastatic resections. Jpn J Clin Oncol 1991;21:211-217.

-12 Trentino P, Rapacchietta S, Silvestri F, Marzullo A, Fantini A: Esophageal metastasis from clear cell carcinoma of the kidney. Am J Gastroenterol 1997;92:1381-1382.

13 Lohsiriwat V, Boonnuch W, Suttinont P: Esophageal metastasis from rectal carcinoma. J Clin Gastroenterol 2005;39:744.

14 Kagaya H, Kitayama J, Hidemura A, Kaisaki S, Ishigami H, Takei J, Kanazawa T, Nagawa H: Metastatic esophageal tumor from cecal carcinoma. Jpn J Clin Oncol 2007;37:628-631. 